\title{
Nonlinear Super-Twisting based Speed Control of PMSG-ECS using Higher Order Sliding Mode Control
}

\author{
Muhammad Waqas Ayub \\ Department of Engineering \\ Lancaster University \\ Lancaster, UK \\ m.w.ayub2@lancaster.ac.uk
}

\author{
Xiandong Ma \\ Department of Engineering \\ Lancaster University \\ Lancaster, UK \\ xiandong.ma@lancaster.ac.uk
}

\begin{abstract}
To harvest the maximum power from an offshore wind energy-conversion-system (ECS), a robust controller is required to run the ECS constantly at the maximum-powerpoint (MPP). The maximum power point tracking schemes are developed via PID (proportional integral derivative) control, a model based SMC (sliding mode control) and a model based STA (super-twisting algorithm) to achieve supreme power from a permanent-magnet-synchronousgenerator (PMSG) based variable speed wind energy conversion system (VSWECS). A detailed comparative analysis is carried out among the three competitors in MATLAB Simulink environment for a random wind energy speed profile. Furthermore, the final simulated results are analyzed and compared with results from standard feedback linearization (FBL).
\end{abstract}

Keywords- ECS (energy-conversion-system); maximumpower-point-tracking (MPPT); PID; SMC (sliding mode control); super twisting algorithm (STA); wind turbine (WT)

\section{INTRODUCTION}

Throughout the ongoing many years, wind turbine is the most solid, inexhaustible, reliable and environmentally friendly power energy source. Therefore, it tends to be utilized as one of the wellsprings of elective energy in future [1]. In view of wind-speed, wind-turbines are characterized as fixed and variable speed. The wind turbine based on variable speed gives $10-15 \%$ further energy output, decreased fluctuation in power, and decreased mechanical-stress than the fixed-speed wind turbine (FSWT) [2]. Therefore, the maximum power can be extracted by applying a wind turbine based on variable speed. A variable speed turbine needs a power-converter, an MPPT scheme and must be competent in supplying a high quality of electric power [3].

The best choices for variable speed are the (PMSG) and doubly fed induction generator (DFIG). The PMSG is more suitable for offshore wind turbine due to gearless transmission capability, high reliability, ease of control and low maintenance cost. The principle preferences of PMSG for offshore wind and wave energy include extremely broad speed range, greater efficiency and high density of power. This prompts a smaller and compact design, petty scale turbine with the capacity to work at minimum speeds [4]. Right now, nine out of the top ten world makers produce wind turbines with PMSG [5]. The extraction of maximum-power from an offshore wind ECS relies upon the speed of wind and the running point (i.e., operation) of the offshore-wind ECS. MPPT is use to increase the efficiency of offshore-wind ECS. The essential idea of driving the MPPT in offshore wind ECS is to adjust and manage the speed of AC generator, along with the speed of PMSG wind-turbine and coupling shaft [3]. Therefore, the implementation of a control scheme to find MPPT for finding the optimal point of operation in offshore-wind ECS is important [1]. There are four major control scheme with MPPT such as tip speed ratio (TSP) methodology, optimal torque (OT) methodology, power signal feedback (PSF) and HCS (hill climb searching), The HCS is referred to as perturb and observe $(\mathrm{P} \& \mathrm{O})[1,2]$. For wind-turbine, a particular ratio called the optimal-TSR is used for the extraction of power maximization. In the TSR algorithm, the TSR is maintained at its optimum at which the captured wind power is raised to maximum by regulating the mechanical speed of the shaft (i.e., of the generator). Although, this algorithm is highly efficient, the need for anemometer makes the system costlier while on the other hand an optimum TSR value is needed for the system, which changes from system to system [2, 7, 8]. Generally, the OT control-scheme is simple to be executed and also efficient and quick. In any case, its proficiency is less than the TSR, due to the restriction of estimating the wind speed straightforwardly [1]. However, there is no such difference between OT and TSR schemes [6].

Unlike TSR, the PSF control technique does not need the measurement of a particular wind speed but it requires a prior information of the wind turbine curve, which is obtained either through tests or simulations for single wind turbine. This way it makes the implementation of PSF control technique costly [8]. Unlike TSR, HCS control technique requires no such prior knowledge of the WTmaximum-power-curve.

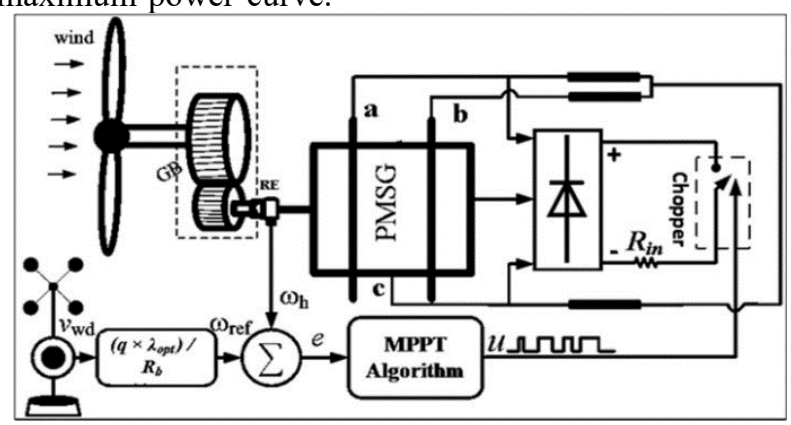


However, under rapid wind speed variations, it fails to achieve MPPT. By selecting an suitable step size is a difficult task, because a greater step size gives a more faster convergence but additional oscillations around the maximum power point, whereas a smaller step-size, although improving efficiency, gives a slower convergence [1].

Most of the complications concerned with these methods can be solved by applying artificial intelligence schemes and also some hybrid control schemes. The FLC (fuzzy logic control) contributes to parameters insensitivity to variation and better convergence [9].

The combination of two different control techniques constitutes a hybrid technique, which utilizes the benefits of first technique to mitigate the problems of the second technique. For example, a hybrid technique was proposed in [6] by merging OT with hill climb search (HCS) to mitigate the problems rendered by HCS: wrong direction under rapid wind speed variations and speed-efficiency trade-off. Similarly, PSF control technique was merged with HCS to develop a flexible and sensor-less technique that applies to all wind types of WTs [1].

In this work, a comparative analysis will be performed among PID, SMC, FBL and STA to extract maximum power. The SMC implies an infinite switching frequency and there is constant control across the sampling intervals. The switching frequency cannot surpass that of sampling which causes chattering in the system. We will demonstrate the proposed STA scheme can guarantee MPPT while reducing the problem of chattering with quick convergence. The remaining parts of the paper is presented as follows; section II covers the modelling of wind ECS. The section III is based on the state equation of the system and normal form conversion from third order to the second order of the system (i.e., from three states variables to two states variables). In section IV, the controller design is carried out, while the comprehensive results and the conclusion are presented in sections $\mathrm{V}$ and VI, respectively.

\section{WIND ENERGY CONVERSION}

In this study, the offshore-wind ECS essentially represents wind turbine based on PMSG, where GB is gearbox, RE is a rotational encoder, $\omega_{h}$ is shaft speed, $\omega_{\text {ref }}$ is reference speed and $e$ represents the error, as shown in Fig. 1.

\section{A. Wind Turbine Model}

The power that is available at the turbine shaft is represented by the subsequent expression [10]:

$$
P_{m}=\frac{1}{2} \rho \pi R_{b}^{2} v_{w d}^{3} C_{p r}(\lambda)
$$

where $R_{b}$ is the radius of WT blade, wind speed is denoted by $v_{w d}, \rho$ shows the mass density of air, while $C_{p r}$ represents the power-coefficient and it is represented as:

$$
\begin{gathered}
C_{p r}(\lambda)=\left[\lambda \left(0.0059-0.0013 \lambda+0.0081 \lambda^{2}\right.\right. \\
\left.-0.00097477 \lambda^{3}\right]
\end{gathered}
$$

From the above equation the value of $\lambda$ is:

$$
\lambda=\frac{w_{s h} R_{b}}{v_{w d} q}
$$

where the symbol $w_{s h}$ depicts the WT shaft angular-speed while, $q$ is the gear-transmission-ratio.

Similarly, one can represent the shaft torque of turbine as a function of coefficient of torque as:

$$
T_{\text {mec }}=\frac{1}{2} \rho \pi R_{b}{ }^{3} v_{w d}{ }^{2} C_{T}(\lambda)
$$

The torque coefficient $C_{T}(\lambda)$ is expressed as:

$$
C_{T}(\lambda)=\frac{C_{P R}(\lambda)}{\lambda}
$$

\section{B. Modeling of PMSG}

A PMSG is modelled in $d q$-axis reference frame and all the details are presented as follows [10].

$$
\left.\begin{array}{c}
\dot{i_{d}}=\frac{-R_{\text {stator }} i_{d}+p\left(L_{q}-L_{\text {chopper }}\right) \omega_{h} i_{q}-R_{\text {chopper }} i_{d}}{L_{d}+L_{\text {chopper }}} \\
i_{q}=\frac{-R_{\text {stator }} i_{q}-p\left(L_{q}+L_{\text {chopper }}\right) \omega_{s} i_{d}-R_{\text {chopper }} i_{q}}{L_{q}+L_{\text {chopper }}}+p \Phi_{m} \Omega_{h} \\
\dot{\omega}_{s}=\frac{1}{J}\left(-p \Phi_{m} i_{q}+\frac{b_{1} v_{w d}}{q}+\frac{b_{2} v_{w d} \omega_{s}}{q^{2}}+\frac{b_{3} \omega_{s}^{2}}{q^{3}}\right)
\end{array}\right\}
$$

where $R_{\text {stator }}, L_{d}, L_{q}$, and $i_{d}, i_{q}$ are the stator-resistance, inductances and currents of $d q$ axis respectively while $p$ expresses the pole number, $\omega_{h}$ is angular rotor speed and $\omega_{s}$ denotes the shaft angular speed of the generator. The $\Omega_{h}$ and $\Phi_{m}$ represent the angular speed and flux of permanent magnets. The symbol $J$ represents the generator shaft inertia, $R_{\text {chopper }}$ represents the equivalent chopperresistance and $b_{1}, b_{2}, b_{3}$ are constant parameters.

The state-variables can be expressed in the simplified form by putting the constant parameters (i.e., as listed in Table I).

$$
\begin{gathered}
x_{1}=i_{d} \\
x_{2}=i_{q} \\
x_{3}=\omega_{s} \\
{\left[\begin{array}{c}
\dot{x_{1}} \\
\dot{x_{2}} \\
\dot{x_{3}}
\end{array}\right]=\left[\begin{array}{c}
-\left(l_{1}+l_{3} R_{\text {chopper }}\right)-\left(l_{3} x_{3}\right)+0 \\
-\left(m_{2} x_{3}\right)-\left(m_{1}+m_{4} R_{\text {chopper }}\right)+m_{3} \\
-\frac{n_{1} v_{w d}{ }^{2}}{x_{1}}-n_{4}-\left(n_{2} v_{w d}+n_{3} x_{3}\right)
\end{array}\right]\left[\begin{array}{l}
x_{1} \\
x_{2} \\
x_{3}
\end{array}\right](7)}
\end{gathered}
$$

where $l_{1}, l_{3}, m_{1}, m_{2}, m_{3}, n_{1}, n_{2}, n_{3}$ and $n_{4}$ are the constant terms and their values are mentioned in the Table I.

\section{STATE EQUATION OF THE SyStem}

The model of wind ECS represented in (7) can be written in the following form:

$$
\begin{array}{r}
\dot{x}=A(x)+B(x) u \\
y=h(x)=x_{3}=\omega_{h}
\end{array}
$$

where $A(x)$ and $B(x)$ are the input matrixes and $x$ describes the state-vector, while $u$ defines the control input.

$$
\begin{gathered}
A(x)=\left[\begin{array}{l}
A_{1} \\
A_{2} \\
A_{3}
\end{array}\right]=\left[\begin{array}{c}
l_{1} x_{1}-l_{2} x_{2} x_{3} \\
-l_{1} x_{2}-m_{2} x_{1} x_{3}+m_{3} x_{3} \\
-n_{1} v_{w d}{ }^{2}-n_{2} v_{w d} x_{3}+n_{3} x_{3}{ }^{2}-n_{4} x_{2}
\end{array}\right] \\
B(x)=\left[\begin{array}{c}
-l_{3} x_{1} \\
-l_{4} x_{2} \\
0
\end{array}\right] \\
u=R_{\text {chopper }}
\end{gathered}
$$

The output value, $\mathrm{y}=x_{3}$, is used to specify which state variables are available for use by the controller. Therefore, 
it is convenient to transform (7) into normal form (i.e., input-output form conversion) by the following way [10]:

$$
\begin{gathered}
G_{1}=y=x_{3} \\
G_{2}=L_{A} h(x)=\frac{\partial h(x)}{\partial x} A(x)=-\gamma_{1}-\gamma_{2} x_{3}-\gamma_{3} x_{3}^{2} \\
-\gamma_{4} x_{2} \\
G_{3}=L_{\mathrm{A}}{ }^{2} h(x)=\frac{x_{1}}{x_{2}}
\end{gathered}
$$

where,

$$
\gamma_{1}=n_{1} v_{w d}^{2}, \gamma_{2}=n_{2} v_{w d}, \gamma_{3}=k_{3}, \gamma_{4}=k_{4}
$$

As the order of our system is larger than the relativedegree (i.e., $n>r$ ), where $n=3$ and $r=2$, therefore the normal form of the system can be written as below:

$$
\begin{gathered}
\dot{G_{1}=G_{2}} \\
G_{2}=L_{\mathrm{A}}{ }^{2} h(x)=L_{B} L_{A} h(x) u
\end{gathered}
$$

where $L_{\mathrm{A}}^{2} h(x)$ is the lie derivative of $h(x)$ in the direction of $A(x)$ and $B(x)$.

$$
\begin{gathered}
\qquad \dot{G}_{3}=\frac{\gamma_{4}}{\gamma_{1}}\left(-\frac{l_{1} G_{3} \gamma_{1}}{\gamma_{4}}-\frac{l_{2} G_{1} \gamma_{1}}{\gamma_{4}}-\frac{l_{1} x_{1} G_{3} \gamma_{1} u}{\gamma_{4}}\right)-\left(\frac{G_{3} \gamma_{1}}{\gamma_{4}}\right)\left(\frac{\gamma_{4}^{2}}{\gamma_{1}^{2}}\right) \\
\left(-\frac{l_{1} \gamma_{1}}{\gamma_{4}}-\frac{m_{2} l_{1} G_{3} G_{1}}{\gamma_{4}}+n_{4} G_{1}-\frac{l_{3} x_{1} \gamma_{1} u}{\gamma_{4}}\right) \\
\text { where } \\
\qquad \begin{array}{c}
L_{\mathrm{A}}{ }^{2} h(x)=-\gamma_{2} A_{2}(x)-\left(\gamma_{2}+2 \gamma_{3} x_{3}\right) A_{3}(x) \\
L_{B} L_{A} h(x)=l_{3} x_{1} \gamma_{4} x_{2}
\end{array}
\end{gathered}
$$

where the zero dynamic state (i.e., $G_{3}$ ) has no significant effects on the output of the system as well as on control input. Consequently, one can neglect it as long as it is stable. It is convenient to show the stability of the zero dynamic term.

\section{A. Stability of Zero Dynamic term}

One can find the internal-dynamic stability by finding the location of zeros [11]. So, by putting $G_{1}, G_{2}$ and u equal to zero in (11), one can get:

$$
\dot{G}_{3}=-G_{3}\left(n_{1}-l_{1}\right)
$$

where as long as $n_{1}>l_{1}$, the internal dynamics are stable.

\section{PROPOSED CONTROL SCHEMES}

In the preceding sections, the control-structure (i.e. normal form) and nonlinear terms i.e., $L_{\mathrm{A}}{ }^{2} h(x)$ and $L_{B} L_{f} h(x)$ are assessed. The primary target is to extract the maximum power from the system, which can be accomplished by planning an appropriate MPPT control technique. This is done via PID, PI-based SMC, supertwisting control law which will be introduced individually in an exhaustive manner.

\section{A. Sliding Mode Control Scheme}

The design model is followed by characterizing surface which called as switching surface. This switching surface is in terms of errors such as the mismatches between two states. The following states are actual and desired. There is a designed control law in the switching-manifold which execute sliding mode alongside with the characterized surfaces. Subsequently, the framework directions are coordinated towards their individual sliding manifolds. The enchantment lies in the manner, when the system dynamics impact the switching surface, the structure of the feedback- loop is adaptively adjusted and the system dynamics slide along the switching manifold. Now the control design, for the reference tracking, can be carried out by defining the tracking error, $e(t)$, as follows:

$$
e_{r}(t)=G_{1}-G_{r e f}
$$

where $G_{1 r e f}=\omega_{\text {ref }}(t)$. Taking the derivative of (14) we have

$$
e_{r}(\dot{t})=\dot{G_{1}}-G_{1 r e f}
$$

In the above equation, the value of $G_{1}=G_{2}$. So equation (15) can be written as

$$
e_{r}(\dot{t})=G_{2}-G_{1 r e f}
$$

Differentiating (16) along (10) and (11), it becomes

$$
e_{r}(t)=L_{A}^{2} h(x)+L_{B} L_{A} h(x) u
$$

A proportional integrated (PI) based sliding surface or manifold can then be designed as:

$$
\begin{aligned}
& \quad S_{m}=G_{2}-G_{1 r e f}+k_{1} G_{1}-G_{1 r e f}+k_{2} \int_{0}^{t}\left(G_{1}-\right. \\
& \left.G_{1 \text { ref }}\right) d \tau
\end{aligned}
$$

where $k_{1}$ and $k_{2}$ are gains. Furthermore, the derivative of manifold along (10) and (11) can be expressed as:

$$
s_{m}=G_{2} G_{1 r e f}+k_{1} G_{2}-k_{1} G_{1 r e f}+k_{2} G_{1}-
$$$$
k_{2} G_{1 \text { ref }}
$$

In this way, a reachability law of the following form is adopted.

$$
s_{m}=u_{d i s}=-k_{3} s_{m}-k_{4} \operatorname{sign}\left(s_{m}\right)
$$

Now, the overall control law by comparing (19) and (20) can be expressed:

$$
\begin{aligned}
& \quad \dot{G}_{2}-G_{1 r e f}+k_{1} G_{2}-k_{1} G_{1 r e f}+k_{2} G_{1}-k_{2} G_{1 r e f}= \\
& -k_{3} S_{m}-k_{4} \operatorname{sign}\left(s_{m}\right)
\end{aligned}
$$

By replacing $G_{2}$ from (10), we have

$$
\begin{aligned}
u= & \frac{1}{L_{B} L_{A} h(x)}\left(G_{1 \text { ref }}-k_{1} G_{2}-k_{2} G_{1}+k_{1} G_{1 \text { ref }} \cdot\right. \\
k_{2} G_{1 \text { ref }} & \left.+L_{A}^{2} h(x)-k_{3} S_{m}-k_{4} \operatorname{sign}\left(s_{m}\right)\right)
\end{aligned}
$$

where $\mathrm{k}$ terms are the gain parameters displayed in Table II from equation (22). In order to get rid of chattering, a super-twisting based algorithm is subsequently proposed:

\section{B. Super Twisting based Algorithm}

As the sliding mode design can produce vibrations around the switching-surface which are not desirable in a practical scenario. Consequently, such vibrations or chattering can be mitigated by adopting the following reachability law:

$$
s_{m}=-p_{1}\left|s_{m}\right|^{2} \operatorname{sign}\left(s_{m}\right)-p_{2} \int \operatorname{sign}\left(s_{m}\right) d t
$$
where $p_{1}$ and $p_{2}$ are constants. The reachability law in (23) has two terms; the first term indicates about the chattering reduction while the second term indicates a low pass filter which eliminates the vibrations (i.e., high frequency oscillations). By comparing (19) and (23), the following control algorithm can be formed. 


$$
\begin{aligned}
& u=\frac{1}{L_{B} L_{A} h(x)}\left(G_{1 r e f}^{\cdot}-k_{1} G_{2}-k_{2} G_{1}+k_{1} G_{1 r e f}^{\cdot}+\right. \\
& k_{2} G_{1 r e f}+L_{f}^{2} h(x)-p_{1}\left|s_{m}\right|^{0.5} \operatorname{sign}\left(s_{m}\right)- \\
& \left.\quad p_{2} \int \operatorname{sign}\left(s_{m}\right) d t\right)
\end{aligned}
$$

where the gain parameters are listed in Table II.

TABLE I

CONSTANT TERMS SPECIFICATIONS [12]

\begin{tabular}{|c|c|c|c|c|c|}
\hline Constant & Value & Constant & Value & Constant & Value \\
\hline$l_{1}=m_{1}$ & 27.147 & $l_{2}$ & 0.94866 & $l_{3}=m_{4}$ & 8.2264 \\
\hline$m_{2}$ & 3 & $m_{3}$ & 1.3146 & $n_{1}$ & 9.945 \\
\hline$m_{3}$ & 0.1332 & $n_{3}$ & 0.00506 & $n_{4}$ & 23.806 \\
\hline
\end{tabular}

TABLE II

DETAIL OF PARAMETERS

\begin{tabular}{|l|l|l|}
\hline Type & Name of Parameters & Magnitude \\
\hline Turbine & Air-density, $\rho$ & $1.25 \mathrm{~kg} / \mathrm{m}^{3}$ \\
& Blade-radius, $R_{b}$ & $2.5 \mathrm{~m}$ \\
& Gear-Transmission ratio, q & 7 \\
\hline PMSG & Stator-resistance, $R_{\text {stator }}$ & $3.3 \Omega$ \\
& Inductance of stator along d-axis $L_{d}$ & $0.0416 \mathrm{H}$ \\
& Inductance of stator along q-axis, $L_{q}$ & $0.0416 \mathrm{H}$ \\
& Equivalent load inductance, $L_{\text {chopper }}$ & $0.08 \mathrm{H}$ \\
& Flux, $\varphi$ & $0.04382 \mathrm{~Wb}$ \\
& Pole number, $\mathrm{p}$ & 3 \\
& Shaft inertia, J & $0.0552 \mathrm{~kg} / \mathrm{m}^{2}$ \\
\hline \multirow{5}{*}{ Controller } & Constant, $K_{1}$ & 60 \\
& Constant, $K_{2}$ & 20000 \\
& Constant, $K_{3}$ & 0.8 \\
& Constant, $K_{4}$ & 200 \\
& Constant, $p_{1}$ & 150 \\
& Constant, $p_{2}$ & 0.08 \\
\hline
\end{tabular}

\section{Simulation Results}

The wind turbine ECS alongside the planned proposed control techniques are simulated in MATLAB Simulink. In the simulations, the wind-speed (i.e., average speed) is assumed as $7 \mathrm{~m} / \mathrm{s}$. In Fig. 1. The optimum TPR $\lambda_{\text {opt }}=7$ and a maximum coefficient of power $\mathrm{C}_{\text {prmax }}=47.6$. To affirm the viability of the control schemes, the designed simulations are performed for a time-frame of $100 \mathrm{sec}$. Initially, the simulations are carried out for conventional based PID and SMC, and then the superiority of proposed STA control-scheme is showed to empower the maximum extraction of the output power. The comparison is made among the designed schemes and standard FBL technique [10]. To ensure the maximum power-extraction, the ECS should be operated at optimal tip speed radio (i.e. $\lambda_{\text {opt }}$ ) in all the designed controller cases by controlling the shaft speed $\omega_{\mathrm{h}}$. By comparing the reference-tracking of PMSG shaft speed, the PID and FBL display oscillatory behavior (i.e. chattering) with significant steady-state errors. The SMC additionally goes through oscillatory tracking around the reference, with a moderately lower amplitude (lower chattering) as compared to the other two techniques. On the other hand, the STA notices an absolute minimum steady state error as compared to the PID, SMC and FBL schemes as depicted in Fig. 2. To obtain the maximum wind power, and operate the wind turbine ECS at the MPPT, the speed of shaft should be controlled in such a manner to ensure the TPR at its optimum value $\lambda_{\text {opt }}=7$, and power-coefficient $C_{p r}$ closed to 47.6.

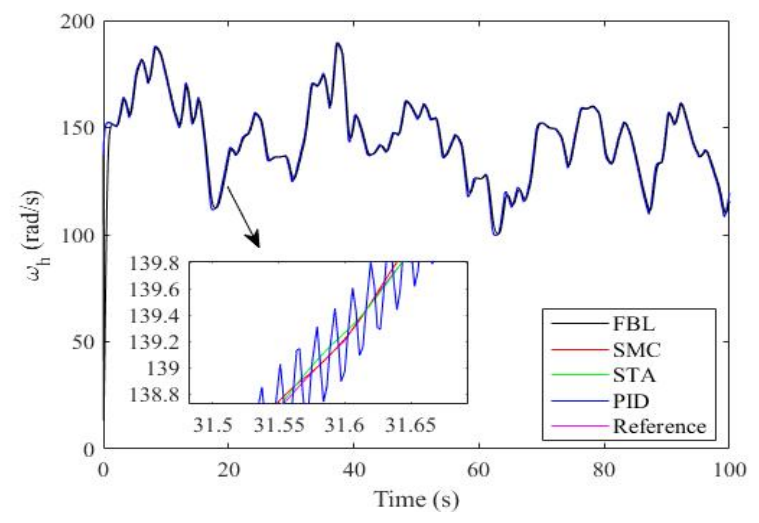

Figure. 2. Reference Speed Tracking of Shaft

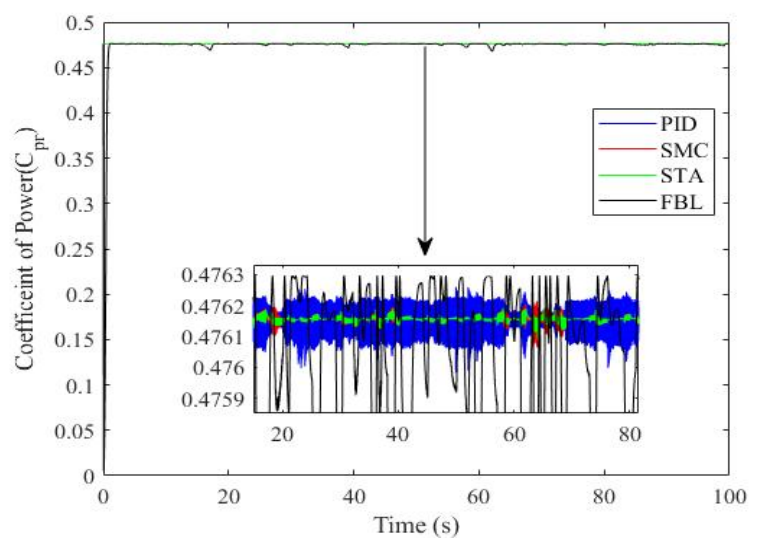

Figure. 3. Coefficient of Power

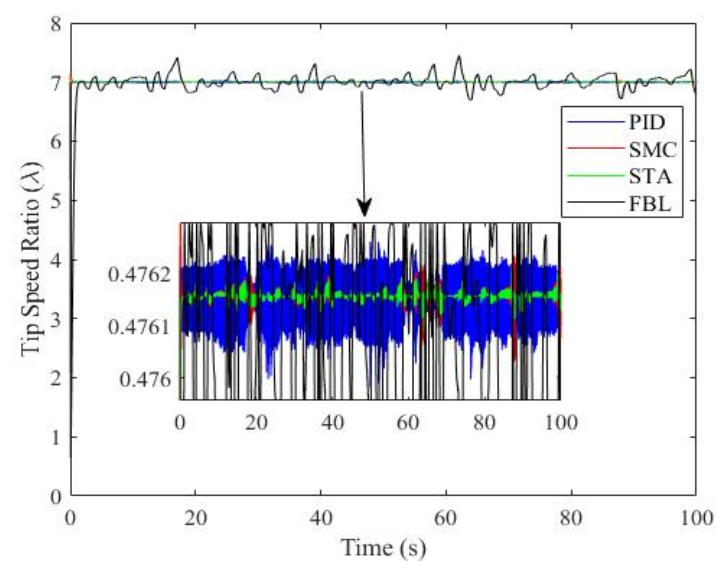

Figure. 4. Tip Speed Ratios 
One can see that in the case of STA, the tip speed ratio is very close to its optimum value and smoothly retains its behaviour for the whole simulation period while other techniques show statistic errors and disturbances which can lower the power extractionas depicted in the zoomed portion of Fig.2 . Due to the stochastic nature of wind, there are abrupt variations in the convergence of power coefficients in the cases of PID, FBL and SMC while no such changes can be observed in the STA case which ensures the maximum extraction of wind power. This can be demonstarted by the tracking of Cpr in the zoom sections of Fig. 3. To tackle the maximum power from wind and decrease chattering, it is important that turbine should be run around ORC (i.e., optimal regime characteristics) of the torque and power. Therefore, it can be seen in the zoomed parts of Fig. 4 and Fig. 5, the STA guarantees the smooth ORC tracking which in turn ensures the reduction of chattering. In Fig. 5 the STA shows better results than PID, FBL and SMC. Fig. 6 shows lots of variations that depict the presence of chattering. In Fig. 6, there are black lines represent FBL due to chattering and the most smooth output is STA that is represented by straight green line.

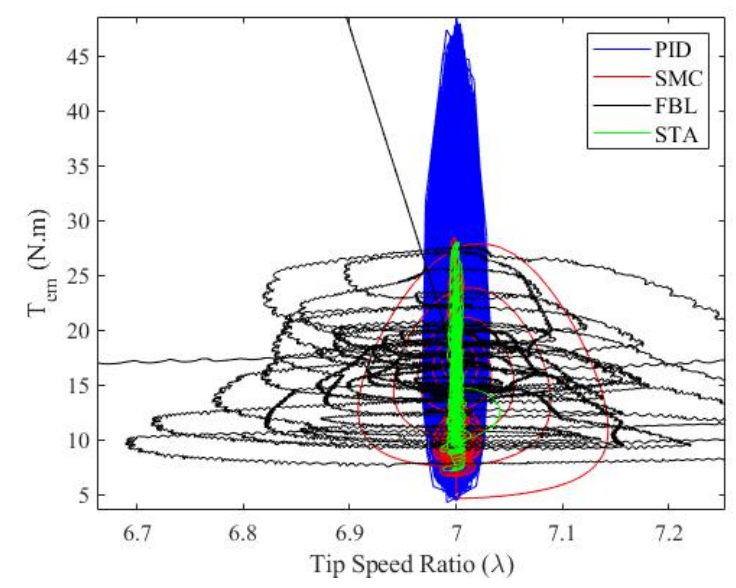

Figure. 5. Tip Speed Ratios Vs Torque

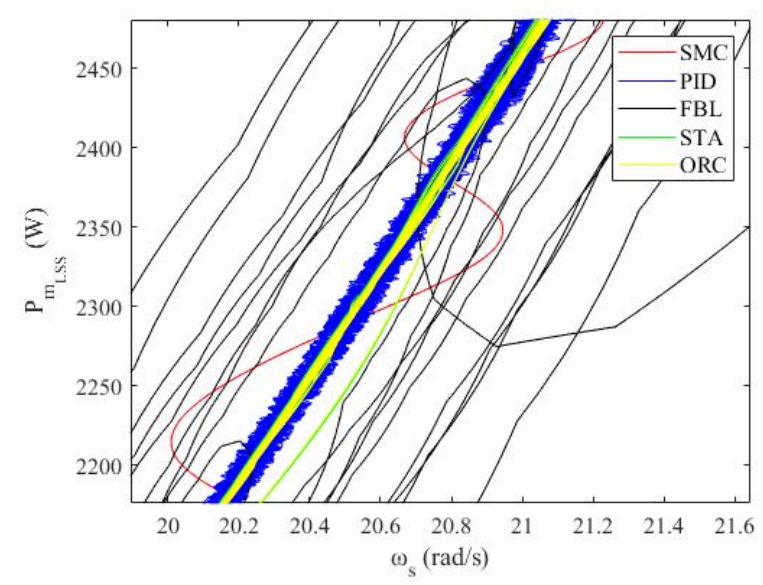

Figure. 6. Shaft Angular Speed Vs Power

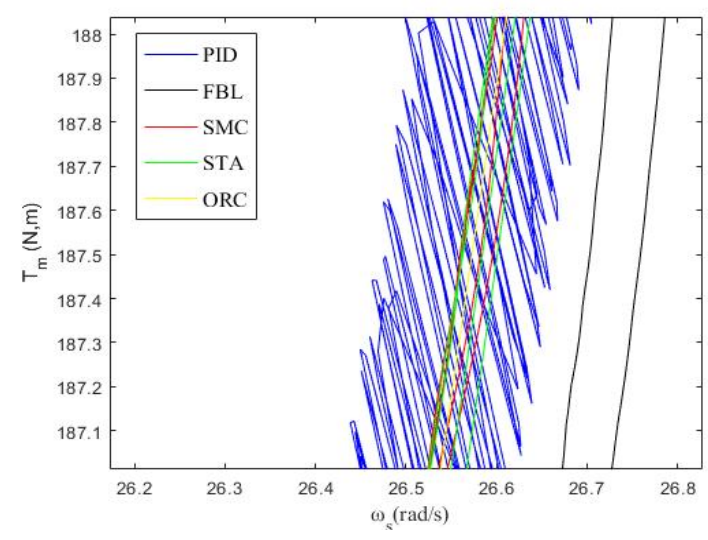

Figure. 7. Shaft Angular Speed Vs Torque

Variations in TPR's Vs torque and the power are given in Fig. 5 and 8, the TPR keeps its optimum value in the STA case. The Fig. 7 shows the shaft speed Vs torque in which STA ensures the MPP, while the other schemes show variations in their tip speed ratios (one can say that MPP is not guaranteed). Also as can be seen from the errors in Fig. 9 in term of shaft speed versus reference speed for the four competitors, STA is more appealing than the other three methods.

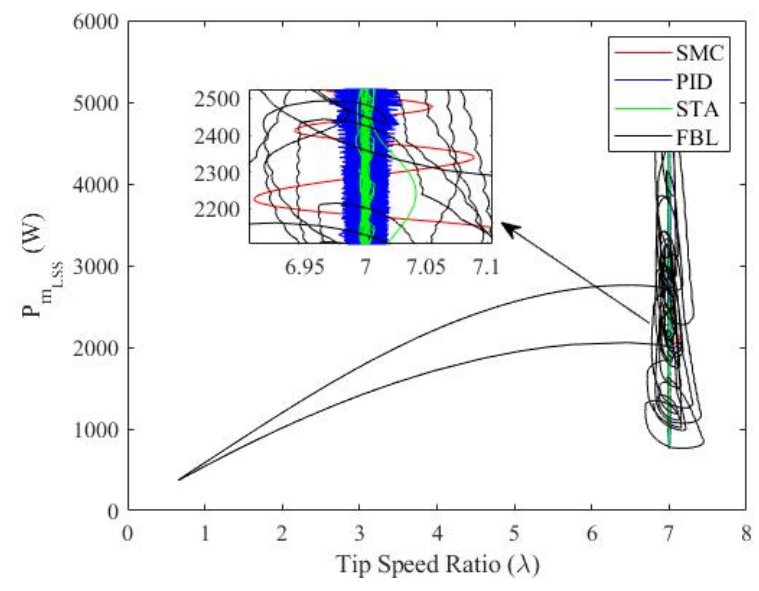

Figure. 8. Tip Speed Ratio Vs Power

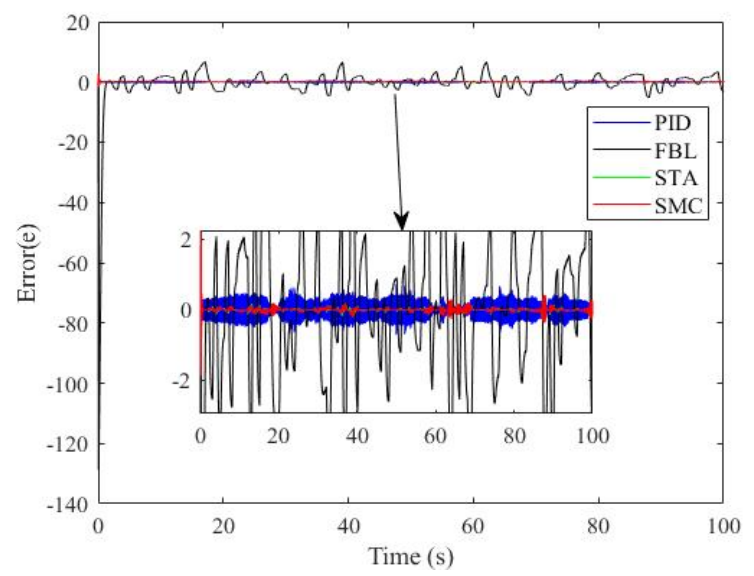

Figure. 9. Errors in term of Shaft speed Vs Reference speed 


\section{CONCLUSIONS}

In this paper, a PMSG based offshore wind turbine ECS is modelled with three state variables which are then transformed into two states or normal form model to simplify the system. The normal form states are then equipped with PID and SMC for the tracking of wind speed in a nominal wind speed profile for evaluation of the controllers. During the simulations, it is demonstarted that PID and SMC are showing oscillatory behaviors (chattering) with some steady state errors that are improved by the discontinuous control component of STA. It is noted that this research is the initial phase of hybrid offshore wind and wave energy. The further work will be based on artificial bee colony algorithm to improve the maximum power acquisition.

\section{ACKNOWLEDGMENT}

The authors gratefully acknowledge the support provided by Lancaster University in terms of the Ph.D. studentship. This research was partially supported by the Royal Society International Exchanges under Grant IEC\NSFC $\backslash 170294$.

\section{REFERENCES}

[1] M. A. Abdullah, A. Yatim, C. W. Tan, and R. Saidur, "A review ofmaximum power point tracking algorithms for wind energy systems,"Renewable and sustainable energy reviews, vol. 16, pp. 3220-3227,2012.

[2] Q. Wang and L. Chang, "An intelligent maximum power extraction algorithm for inverter-based variable speed wind turbine systems,"IEEE Transactions on power electronics, vol. 19, pp. 1242-1249, 2004.

[3] Baroudi, Jamal A., Venkata Dinavahi, and Andrew M. Knight. "A review of power converter topologies for wind generators."'Renewable energy32, vol no. 14: 2369-2385, 2007.

[4] Housseini, Boubacar, Aime Francis Okou, and Rachid Beguenane. "Performance comparison of variable speed PMSG-based wind energyconversion system control
algorithms.'In 2017 Twelth International Conference on Ecological Vehicles and Renewable Energies (EVER),pp. 1-10. IEEE, 2017.

[5] Yaramasu, Venkata, Apparao Dekka, Mario J. Dur'an, Samir Kouro, and Bin Wu. "PMSG-based wind energy conversion systems: survey onpower converters and controls." IET Electric Power Applications11, vol no. 6: 956-968, 2017.

[6] S. M. R. Kazmi, H. Goto, H.-J. Guo, and O. Ichinokura, "Review andcritical analysis of the research papers published till date on maximum power point tracking in wind energy conversion system," in IEEE Energy Conversion Congress and Exposition, pp. 4075-4082, 2010.

[7] C. Wei, Z. Zhang, W. Qiao, and L. Qu, "An adaptive network-based reinforcement learning method for MPPT control of PMSG wind energy conversion systems," IEEE Transactions on Power Electronics, vol. 31,pp. 7837-7848, 2016.

[8] S. M. Barakati, M. Kazerani, and J. D. Aplevich, "Maximum power tracking control for a wind turbine system including a matrix converter,"IEEE Transactions on Energy Conversion, vol. 24, pp. 705-713, 2009.

[9] M. Simoes, B. K. Bose, and R. J. Spiegel, "Design and performanceevaluation of a fuzzy logic based variable speed wind generation system," in IEEE Industry Applications Conference Thirty-First IAS Annual Meeting, pp.349-356, 1996.

[10] Y. Soufi, S. Kahla, and M. Bechouat, "Feedback linearization control based particle swarm optimization for maximum power point trackingof wind turbine equipped by PMSG connected to the grid,"International journal of hydrogen energy, vol. 41, pp. 20950-20955, 2016.

[11] Y. Bazargan-Lari, M. Eghtesad, and B. Assadsangabi, "Study of internaldynamics stability and regulation of globular spray mode of GMAW process via MIMO feedback-linearization scheme,"in International Conference on Intelligent Engineering Systems, pp. 31-36, 2008.

[12] Khan, Malak Adnan, et al. "Observer Based Higher Order Sliding Mode Control Scheme for PMSG-WECS." 15th International Conference on Emerging Technologies (ICET) IEEE, pp. 1-6, 2019. 